\title{
Staffing of agrarian economy: challenges and solutions
}

\author{
G. R. Fassakhova, F. T. Nezhmetdinova*, N. Kh. Sharypova, and N. N. Hamidullin
}

Kazan State Agrarian University, 420015 Kazan, Russia

\begin{abstract}
Today there are serious difficulties in staffing of agricultural economy. The article analyzes the reasons for the decline in the level of staffing in this sphere. There are objective factors that are associated with the urbanization process at the global and regional levels. In Russia this is accompanied by the change in $t$ social expectations of rural youth. At the same time, there is still a rather high need for staffing in specific sectors of agriculture. It is obvious that with the introduction of digital technologies and modern agrobiotechnologies, automation and robotization of agricultural sector, the list of specialties and competencies of agricultural workers will expand. The authors pay due attention to the problems of employment of graduates of agricultural universities. As an example of a positive solution to this problem, the issues of organizing employment of graduates of Kazan State Agrarian University (KSAU) are considered. The authors believe that the paper will be useful to the heads of agro-industrial complex and agricultural universities in the further development of theoretical and practical issues of agricultural sector staffing.
\end{abstract}

\section{Introduction}

The current state of labor market reflects the ambiguity of the processes in the field of employment, due to the influence of economic and social transformations in the country. Agriculture, which is one of the most important strategic areas of the life of Russian society, annually attracts no more than $30 \%$ of graduates of agricultural universities [1]. Graduates who can find work in the city are not oriented towards employment in the countryside. Graduates majoring in specialties directly related to agricultural activities (engineers, agronomists) are more focused on employment in the countryside.

However, many do not want to go to the village or leave this field of activity soon. The following aspects influence the reluctance to find employment in the countryside:

-low level of income and housing provision in rural areas;

- rural labor features;

- a narrow range of vacancies for specialists in the countryside;

- low rating of the prospects for their own development and career;

- low rating of a village as a comfortable place to live;

- low rating of the conditions for meeting the social needs of communication and the needs of personal development and development of future children;

- financial instability of agriculture, etc. [2].

It is necessary to mention the serious problems in agriculture related to attracting or returning young people to the countryside. At present, the share of graduates with higher agricultural education returning to their places of residence does not exceed $30-40 \%$ in Russia as a whole (even in terms of targeted training). However, this indicator for KSAU is much higher about $70 \%$. The lack of social infrastructure, low wages, and insufficient prestige of work in rural areas reduce the motivation of young people to work in agriculture.

The inaccessibility of vocational education and advanced training at the place of residence, the high dependence of work in agriculture on climatic conditions, significant financial costs (travel to the place of study, living in a hostel, etc.) lead to an outflow of young people and qualified personnel to the city, exposing and undermining the agricultural system as a whole.

There is no opportunity for a graduate of an agricultural university to work in a specialty and in a city. It is almost impossible for a graduate of an agricultural university with the qualifications of an "agronomist" or "zootechnician" to find a job in a modern city. This forces young specialists to look for their mission in other areas of activity. The consequence of this is the irreversible loss of young specialists in agricultural sector and the devaluation of the knowledge gained at university.

At the same time, it is necessary to note that in recent years the specialties that involve work in the city after agricultural university appeared: the positions in municipal sector (gardening and landscape construction, decorative gardening, etc.); food processing; home veterinary medicine; the positions in the service sector (health-saving and recreational technologies, cynology and felinology, landscape design, etc.). At the same time, in agricultural universities, there is still no intention of

다responding author: nadgmi@mail.ru 
training specialists for this kind of work. In addition, new urban professions based on agricultural technologies do not imply mass training of specialists [3].

At the same time, we should admit that there is insufficient scientific and regulatory support for training personnel and specialists of agro-industrial complex. There is also no annual monitoring of the identification of the needs for specific specialists. There are no predictive and advanced models for changing the cluster of specialties for agro-industrial complex. There is no systematic approach linking the needs of agricultural production on the one hand and social infrastructure in the countryside on the other. There is weak regulatory framework for the creation of new forms of interaction at all levels of education, taking into account the specifics of the industry, etc. All of the above mentioned aspects hinder the adequate reproduction of qualified personnel for agro-industrial complex [3].

The purpose of the research is to analyze and generalize many years of work on the employment of graduates of Kazan State Agrarian University in order to provide the industry with qualified personnel.

The authors of this article conducted a survey of graduates, studied the experience of employment of graduates of agricultural universities and Russian and foreign researchers who study the problems of employment of graduates of agricultural universities and labor market monitoring.

\section{Materials and methods}

The research methods are presented by the study of theoretical and practical experience of the university on this research topic. The authors distinguish the following groups of methods that help to solve the problem of successful employment of graduates 1) questioning students, 2) methods for monitoring the future career of graduates, 3) methods of researching the work of teachers, 3) methods of career guidance with school graduates, 4) methods of cooperation with leaders of agricultural enterprises to monitor the labor market.

The novelty of the research is in the fact that the authors analyze the labor market in the agricultural sector and the ways to solve the problems of successful employment of their graduates.

The result of the study is the assistance in the solution of problems of employment of KSAU graduates.

\section{Results and discussion}

According to the research, one of the main problems of uncertain behavior of graduates in labor market is the lack of work experience in their specialty. For this reason an employer often refuses to hire a young specialist.

The prestige of a particular profession is also influenced by its demand in labor market. In our opinion, there is another important factor that seriously affects the popularity of agricultural specialties among young people. In scientific research and public opinion of
Russian citizens, including the Republic of Tatarstan, the idea of the underdevelopment of rural way of life and work has developed [3, 4]. Modern young people in their future do not want to associate themselves with the past. A large number of technologies in agricultural production and types of livelihoods in the countryside change much more slowly than in urban environment. The pace of life in rural areas, reliance on traditions and continuity come into conflict with the values of the innovation and information space of big cities, its infrastructure $[4,5]$. This coincides with the fact that the social approval or prestige of work in agricultural sector is not supported in society and by the parents of rural school graduates.

At the same time, technological innovations are rapidly spreading in agricultural sector, they are as follows: robotics and autopilot agricultural equipment, artificial intelligence and information technology, the creation of artificial agrobiocenoses, genetic engineering etc. [6].

Today we can talk about the need to develop master's programs in such areas as: smart agriculture; robotization of production in agro-industrial complex; urban agriculture and vertical cultivation; intelligent technologies for food waste processing and resource conservation; genetic engineering and cultivation of high-yield crops; IoT in agriculture; bioeconomics and biotechnology; geo- and bioinformatics, etc.

For the successful training of engineering and scientific personnel for digital transformation of agricultural production, new professional standards are also needed providing such new professions as: agroinformatics, agrocybernetic, GMO-agronomist, city farmer, agricultural ecologist, systemic biotechnologist, energy auditor, engineer of robotic systems in agriculture, living systems architect, virtual agrarian environment architect, meteorological engineer, agricultural robot designer, park ecologist, agronomisteconomist, food net specialist, operator of automated agricultural machinery, specialist in specific agriculture, etc. [7].

The problems of staffing of agro-industrial complex slow down the pace of practical implementation of state projects and significantly reduce the effectiveness of state policy in relation to the agrarian sector of economy [8].

According to national and international experts, the reduction of the risks of effective development and support of agrarian education will require the recognition of the concept of multifunctionality of the agrarian sphere, which performs not only the function of food supply for the country's population, but also the most complex function of the social structure of rural population life and sustainable development of rural areas $[9,10]$. In addition, it is necessary to mention the vital ecological function of preserving and increasing the fertility of agricultural land, agricultural landscapes and land reclamation and safety provision of flora and fauna biodiversity [11].

All these factors resulted in the development of effective mechanisms for attracting, motivating and 
employing its graduates in agriculture for the professional education of the agrarian profile [12]

The agriculture of the Republic of Tatarstan (RT) occupies one of the leading positions in the Russian Federation (RF) and among its constituent entities of the Volga Federal District. Agricultural producers use 45.4 thousand square kilometers of land, of which arable land is 32.3 thousand square kilometers. In rural areas of the republic 912.6 thousand people or $23.6 \%$ of the population live and 59.5 thousand people or $4.4 \%$ of all employees work. The agriculture of the Republic of Tatarstan is one of the leading in Russia. The republic is in $4^{\text {th }}$ place among the regions of Russia in terms of the value of gross agricultural production and in first place in the Volga Federal District.

The Republic of Tatarstan, possessing $2.3 \%$ of the country's agricultural land, produces $4.3 \%$ of agricultural products, including $3.5 \%$ of meat (468.5 thousand tons), $6 \%$ of milk (1751 thousand tons). The Republic of Tatarstan firmly occupies a leading place in the Russian Federation for the production of livestock products (the $1^{\text {st }}$ place for the production of commercial milk, the $4^{\text {th }}$ place for cattle and poultry meat). The republic is selfsufficient in terms of basic products.

According to the republican Program "Development and deployment of the productive forces of the Republic of Tatarstan based on the cluster approach until 2020 and for the period until 2030", the purpose of the long-term development of the agro-industrial complex of the Republic of Tatarstan is the development and stimulation of efficient production of agricultural products in the republic as a material basis for economic growth provision in agro-industrial complex, improving the quality of life of the rural population and ensuring food security of the Republic of Tatarstan, increasing the competitiveness of agricultural products.

According to this purpose, the tasks of the agroindustrial complex of the Republic are as follows:

- the attraction of financial resources of large investors for the implementation of highly effective investments in the agro-industrial complex;

- the creation of conditions for increasing the competitiveness of products of the agro-industrial complex and fishery, providing the population with highquality food products;

- the sustainable development of rural areas, ensuring employment and improving the living standards of rural population;

- the creation of conditions for the preservation and reproduction of used agriculture, fishing and natural resources;

- the increase in crop production based on increasing the yield of the main types of agricultural crops;

- the increase in livestock production based on increasing the productivity of livestock and poultry;

- the increase in the levels of consumption of the main types of agricultural products and food, their availability and environmental safety for the population;
- the increase in financial standard of living, improving working conditions and employment of rural population;

- the improvement of housing and social living conditions of the population in rural settlements;

- the improvement of the institutional structure of agricultural production by supporting the development of large forms (agricultural firms, agricultural holdings) and small forms of farming;

- the increase of the role of management factors, informatization and science in the sustainable development of agricultural production.

One of the main priorities of the Strategy 2030 is the formation of the agro-industrial cluster of the Republic of Tatarstan.

- Key measures for the development of the Cluster of AIC:

- Model changing: from priority support of large holdings to balanced support of the participants of the Agro-industrial cluster (balance of large, medium and small enterprises, with an emphasis on the expansion of their interaction).

- The development within the cluster of industry unions / associations in order to stimulate interaction between government and business and regulate industry markets.

- The adjustment of support: from supporting farms to supporting the implementation of priority investment projects for the development of the agroindustrial complex of the Republic of Tatarstan.

- Monitoring the efficiency of the agro-industrial complex at the level of the republic as a whole and at the level of implementation of priority investment projects in the agro-industrial complex.

- The focus on the production of environmentally friendly products.

- Cluster branding and product promotion, with a focus on environmentally friendly products.

- The creation of a regional electronic platform the portal of the Cluster of the agro-industrial complex of the RT (supply and demand of suppliers and consumers of products)

- The development of rural areas - the formation of a new agricultural structure, through the support of smal and medium-sized enterprises in the agro-industrial complex and the comprehensive social development of rural areas.

- The development of social infrastructure and reduction of the outflow of "valuable" human capital from rural areas by stimulating the launch and implementation of new investment projects.

- A three-level system for the placement of economic and social objects of the agro-industrial complex: large, medium and small.

- The stimulation of access of agricultural producers to retail markets through the development of a storage and marketing system for cluster products.

- The reformation of enterprises participating in the cluster of the agro-industrial complex of the Republic of Tatarstan.

- The stimulation of import substitution. 
- The creation of a system for minimizing risks (natural, technogenic and market).

- The optimization of the management system of the agro-industrial complex of the Republic of Tatarstan.

According to the above mentioned aspects, we can draw a conclusion about the main priorities for the development of agriculture in the Republic of Tatarstan:

1. The provision of the volume of production of the main types of agricultural products necessary to meet the needs of the population of the Republic of Tatarstan for food, processing industry and related industries - in raw materials according to the appropriate quality parameters and at affordable prices, effective import substitution in agricultural market.

2. The increase of the competitiveness of agricultural production, optimizing the specialization and concentration of production, ensuring the accelerated development of priority sectors of agriculture, improving and increasing the productivity of land resources and animals.

3. The development and implementation of innovative technologies for processing agricultural products.

4. The improvement of material, technical and market infrastructures in rural areas.

5. The provision of the socio-economic development of rural areas and the creation of favorable living conditions for rural population.
6. The increase of the compliance with the requirements of economic security, preservation and restoration of the environment and the efficient use of natural resources.

All this requires the advanced development of the personnel potential of agriculture, as the main carrier of innovative knowledge and skills and as the main condition for the development of modern methods and technologies in the production and management of enterprises in the agro-industrial complex.

Several years ago, within the framework of modeling and forecasting staffing needs, the Center for Strategic Assessments and Forecasts (KFU) and the Center for Advanced Economic Research conducted a study "Assessment and prospects for the development of the regional market of educational services in interaction with the needs of labor market in Privolzhsky federal district (through the example of the Republic of Tatarstan)" [13].

The study revealed the characteristic trends in the development of the expected imbalance and the predicted general needs of Tatarstan economy, taking into account the number of working-age population in the context of enlarged groups of specialties, providing the maintenance of existing approaches to the formation of development processes in the labor market, as well as in the field of educational services in the Republic of Tatarstan (Tables 1, 2, 3).

Table 1. Results of forecast calculations

\begin{tabular}{|l|c|c|c|c|}
\hline \multicolumn{1}{|c|}{ Indicator } & 2012 & 2015 & 2020 & 2030 \\
\hline $\begin{array}{l}\text { Total employment in the Republic of } \\
\text { Tatarstan }\end{array}$ & 1861349 & 1910803 & 2172950 & 2431623 \\
\hline Additional staffing requirements & 40949 & 42037 & 47804 & 53495 \\
\hline $\begin{array}{l}\text { General need of the Tatarstsan economy in } \\
\text { staff }\end{array}$ & 1902299 & 1952841 & 2220755 & 2485119 \\
\hline Working-age population & 2366678 & 2346947 & 2623996 & 2865573 \\
\hline $\begin{array}{l}\text { Expected imbalance of predicted total needs } \\
\text { of the economy with the number of working- } \\
\text { age population in the context of large groups } \\
\text { of specialties }\end{array}$ & 464379 & 394106 & 403241 & 380453 \\
\hline Labor resources, people & 2484462 & 2527548 & 2715922 & 2923827 \\
\hline $\begin{array}{l}\text { Population distribution } \\
\text { labor resources: }\end{array}$ & & & & \\
\hline Agriculture, hunting and forestry & 183385 & 184978 & 190255 & 187144 \\
\hline Fishing, fish farming & 587 & 592 & 609 & 599 \\
\hline
\end{tabular}

Table 2. Forecast structure of personnel needs in the economy of the Republic of Tatarstan, people

\begin{tabular}{|l|c|c|c|c|}
\hline $\begin{array}{l}\text { Total need for personnel in the context } \\
\text { of foreign economic activity }\end{array}$ & 2012 & 2015 & 2020 & 2030 \\
\hline $\begin{array}{l}\text { Distribution of the number of labor } \\
\text { resources: }\end{array}$ & & & & \\
\hline Agriculture, hunting and forestry & 171207 & 175756 & 199868 & 223661 \\
\hline Fishing, fish farming & 514 & 527 & 600 & 671 \\
\hline
\end{tabular}

Table 3. Forecast of training specialists in different areas, people

\begin{tabular}{|l|c|c|c|c|}
\hline & & 2020 & 2025 & 2030 \\
\hline Economics and management & 080000 & 2499 & 2619 & 2690 \\
\hline Agronomy & 110200 & 160 & 167 & 172 \\
\hline Automotive and tractor construction & 190201 & 134 & 140 & 144 \\
\hline Informatics and computer engineering & 230100 & 158 & 166 & 170 \\
\hline
\end{tabular}


The forecasts given in the context of the agrarian sector of the Republic of Tatarstan largely remain relevant and a number of them require serious adjustment. First of all, we are talking about the accelerated introduction of digital technologies in agriculture. However, this is subject of additional research.

Today KSAU is one of the leading universities of the republic, providing training of qualified staff for forestry and agriculture in more than 50 educational programs. Career guidance work, analysis, situation on the labor market, professional consultation, the Center for PreUniversity Education and Graduate Employment and the Center for Corporate Cluster Training of KSAU, which also includes nine institutions of secondary vocational education, are actively involved in this activities [14]. In general, educational institutions within the cluster solve the following tasks:

a) the improvement of the efficiency and quality of educational process;

b) the adaptation of graduates to social, economic and cultural needs of society and changes in the labor market;

c) the increase in the efficiency of the use of their intellectual, material and information resources in their work;

d) the establishment of cooperative ties with nonprofit organizations and enterprises in innovative sectors of the economy;

e) the active use of their positive experience in scientific and educational activities, professional and pedagogical skills.

The educational institutions of the scientific and educational cluster of agro-industrial complex of the Republic of Tatarstan develop inclusive multi-level educational programs in related agricultural specialties of primary, secondary and higher education providing continuity and shortening of training periods within the cluster.

Basic enterprises of the annually apply for the inclusion in the government contract for the training of workers and specialists, they send the most promising workers for additional vocational education and conduct career guidance work in schools in order to ensure enrollment.

In order to achieve the main purpose - the employment of graduates, the center implements a whole range of actions aimed at the solution this purpose. The center cooperates with enterprises and organizations of agribusiness in the region, organizes joint events aimed at assisting in employment. Students of different ages visit these events. The collected information on the needs of personnel, enterprises and organizations of the agribusiness of the Republic are given to the graduates. The university traditionally carries out the so-called "distribution". It runs from April to May. The enterprises submit the applications for students. In addition to employment, the Center monitors the employment of graduates. Monitoring is carried out through telephone interviews of graduates, appeals to the agricultural departments of the municipal districts of the region and personnel services of organizations and enterprises. According to the results of the survey, a database is formed, where information on the real employment of the graduate is registered.

In order to increase motivation in training in agricultural specialties, Kazan State Agrarian University and together with the Ministry of Agriculture and Food of the Republic of Tatarstan started a program of targeted training of personnel for the agro-industrial complex. This training is carried out on the basis of an agreement: an organization of the agro-industrial complex - a student. According to this program, organizations conclude agreements with students during their studies at university and according to which, they pay a scholarship in the amount of 10,000 rubles monthly throughout the entire period of study.

In return, a student agrees and undertakes to work in this organization for at least three years after graduation, or, in case of refusal, is obliged to compensate the costs for training.

In addition, according to the agreement, an enterprise actively participates in the training of a student, organizes work experience internship for him, gives him a mentor and provides employment in his specialty with a salary of at least the average for the region.

Such a system of targeted training is motivated and attractive to young people. At the same time, it significantly increases the responsibility of each party for the decision.

\section{Conclusion}

Thus, in order to increase the prestige and quality of agricultural education, it is necessary to strengthen social and corporate interaction with all stakeholders. To do this, Kazan State Agrarian University has necessary tools and seeks to:

- comprehensive diagnostics and monitoring of the labor market needs in agro-industrial complex and rural areas; life strategies and professional trajectories of graduates, both schools and agricultural educational institutions;

- study the market of customers of educational services and scientific results; positions in agricultural technology and commodity markets, work to develop stakeholder feedback mechanisms;

- be engaged in planning the career of students of rural schools and technical schools through the organization of career guidance work,

- develop and implement a career planning system at all stages of multilevel agrarian education;

-help in the creation of specialized classes of agricultural areas;

- distribute and promote modern achievements in agriculture among the inhabitants of rural areas, primarily for the organization of continuous education for children, youth and adults, sustainable development of rural areas and the preservation of cultural traditions. 
- take part in the formation of a state target program for supporting young scientists, teachers, graduates of agricultural universities, trained in extremely deficient agricultural specialties, who want to work in the countryside; take part in programs such as affordable housing and provide exemption from compulsory military service, good salary, etc.

All these measures help to reduce costs and increase the employment rate of its graduates, as a result, to stabilize the staffing of the personnel sector.

\section{References}

1. T.V. Abankina, A.N. Krasilova, G.A. Yastrebov, Education as a start for life: life plans of rural schoolchildren in Russia, Education Issues, 2, 87 (2012)

2. M.M. Bakhtin, Modern problems of employment of graduates of agricultural and economic universities, System management, 4(13), 1-6 (2014) Available at: http://sisupr.mrsu.ru/2011-4/PDF/11/Nacharkina.pdf

3. F.T. Nezhmetdinova et al., Employment of graduates of agricultural universities and their careers, Rural machine operator, 6, 2-3 (2017)

4. G.G. Sillaste, The influence of the media on the life plans of rural students, Sociological research, 12, 95-102 (2004)

5. P.A. Mikheev, Dynamics of life values of rural youth, Sociological Research, 1, 91-94 (2005)

6. F. Nezhmetdinova et al., Global challenges for agrarian sector of Russian economy and it human resources, Revista Espacios, 39(26) (2018)

7. Atlas of new professions, available at: http://www.skolkovo.ru/public/media/documents/res earch/sedec/SKOLKOVO SEDeC Atlas 2.0.pdf.

8. F. Nezhmetdinova et al., The problem of choice labor activity for university graduates in Russian
Federation, Int. J. of Mechanical Engineering and Technology, 9(3), 661-769 (March 2018)

9. C. Potter, M. Tilzey, Agricultural multifunctionality, environmental sustainability and the WTO: Resistance or accommodation to the neoliberal project for agriculture? Geoforum, 38(6), 12901303 (November 2007)

10. G. van Huelenbroeck, G. Durando (eds.), Multifunctional Agriculture. A New Paradigm for European Agriculture and Rural Development (Ashgate, Hampshire - Burlington, 2003)

11. S. Barot, V. Allard, A. Cantarel et al., Designing mixtures of varieties for multifunctional agriculture with the help of ecology. A review, Agron. Sustain. Dev., 37, 13 (2017) Available at: https://doi.org/10.1007/s13593-017-0418-x

12. N.I. Fedoryaka, The problem of employment of graduates of agricultural universities and ways to solve them at Michurinsky Agrarian University, available at: http://www.mgau.ru/file_article/ article_655_622.pdf

13. L. Shakirova, L. Elshin, M. Prygunova, Assessment and prospects for the development of the regional market of educational services in interaction with the needs of the labor market in the Volga Federal District (on the example of the Republic of Tatarstan), Electr. Econ. Bull. of Tatarstan, 60-79 Available at: https://cpei.tatarstan.ru/file/ $\%$ D0\%AD\%D0\%92 09.2012.pdf

14. G.R. Fassakhova, K.I. Sibgatova, I.T. Sabirov, V.V. Sadovaya, L.P. Yatsevich, Pedagogical Potential of the Career Guidance Course "Professional Career Planning" to Form Pupils and Students' Self-determination in the Integrated System "School - Vocational College," Review of European Studies, 7(1), 80-85 (2015) 